\title{
Complex Adaptive Leadership for Organization and Human Development
}

\author{
Ivy Johnson-Kanda ${ }^{\mathrm{a}}$ and Robert M. Yawson ${ }^{\mathrm{b} *}$ \\ ${ }^{a}$ Department of Entrepreneurship \& Strategy, School of Business, Quinnipiac University \\ ${ }^{\mathrm{b}}$ Department of Healthcare Management and Organizational Leadership, School of Business, Quinnipiac University \\ *Email: robert.yawson@qu.edu
}

\begin{abstract}
Complex Adaptive Leadership offers ways to shift the focus of practice to one that reflects, embraces multiple points of view, and changes in response to new knowledge and data. From a societal perspective, complex adaptive leadership provides organizations with the opportunity to grapple with the most significant and persistent problems of our time and potentially achieve real change. The paper explores complexity theory in more detail and its influence on social systems using gender bias and terrorism as examples. Using the Human Security Framework as a complex adaptive leadership approach in addressing Wicked Problems, this paper describes the Human Security dimensions to understand the wicked problems in which 21 st-century organizations grapple with and the type of organizational leadership needed to confront these challenges.
\end{abstract}

Keywords

Complexity

Theory; Adaptive

Leadership;

Wicked Problems

\section{COMPLEX AND UNCERTAIN WORLD}

For today's companies and organizations to thrive, adapting to constant change is necessary. Today's global, fast-paced environment makes it impossible for inflexible organizations to exist. The challenges of $21^{\text {st }}$ century leadership are unprecedented and rooted in managing complexity and uncertainty, decentralized organizational structures and culture, and globalized ideologies. The trend toward unpredictable events in a globalized environment requires organizational structures and cultures that are less controlling and determining but instead generating flexibility and creativity to respond to chaotic events. Businesses and leaders must focus on the change in complexity faced in today's world. The solutions of the past no longer speak to the challenges of today. "Turbulence is not new but with continued globalization, increased complexity, accelerating speed of information exchange and market volatility we are now facing reality almost unrecognizable to previous generations" (Lane \& Down, 2010:514).

To be able to face these new and constant challenges, leaders must change their approach and adopt a more adaptive leadership approach. The role of leadership has continued to evolve as dynamically as the turbulent environments in which it operates. Traditional administrative leadership techniques, focused on driving alignment and control, are ineffectual if used alone in times of ambiguity and emergent changes. "This is a classic error of trying to force a chaotic space to operate as if it were a rational space” (Lane \& Down, 2010:524). Managing 
change is no longer just an operational exercise but a core competency for all organizations who aim to exist in the future and cannot be prescribed by a management model (Surdu \& Potecea, 2013). To compound these complexities, leaders around the world are now faced with pressures to form productive global teams and culturally collaborative networks shifting the strategic narrative from domestic interests toward a global mindset. In complexity terms, management must be seen as a social enterprise with the interests of purpose focused on meeting the broader needs of society as a whole (Drucker, 1998).

According to Drucker (1998), complexity theory aims to address the change in leadership to managing an organization as a social enterprise and a way to address the volatility of today's markets. "It is concerned with appreciating how sudden and unpredictable changes occur after a period of stability identifying that there are no pre-fixed destinations instead there are potentials" (Lane \& Down, 2010: 514). Outcomes are becoming less predictable and yet many of the tools we use to understand the world we face are inadequate for the purpose (Lane \& Down, 2010). "This is because they assume that there is such a thing as an ordered and objective reality that we can uncover with increasingly sophisticated techniques based on linear cause and effect scenarios" (Lane \& Down, 2010: 515). As Senge, Smith, Kruschwitz, Laur, and Schley (2010: iv) put it, there is demand for 'the necessary revolution.' Senge et al., (2010) contend that we are at the end of the industrial age and a new revolution is emerging out of the industrial 'bubble.' The people leading this revolution demonstrates mastery of three core areas that undergird organizational learning. (1.) learning how to see the larger systems. (2.) Understanding the importance of collaborating across boundaries "that previously divided them from others within and outside their organizations" (Senge et al., 2010: 44). And, (3.) "moving away from reactive problem-solving mode to creating futures they truly desire" (Senge et al., 2010: 44).

Linear epistemology has been the dominant epistemology in the field of management and as such undergirds a majority of models used in all aspects of organizational leadership and decision making.

Although a linear epistemology's usefulness is implicit in its widespread impact on models and on their use, a linear epistemology has several limitations, including a tendency to privilege particular Western cultural and masculine worldviews, short-term measures, and effects close to the organization (Jayanti, 2011: 101).

Drucker (1998) argued that management and business is a social enterprise, i.e., to serve the broader needs of society, with relationships being the critical determiner. We should also understand that we are dealing with non-linear relationships that characterize complex human systems.

Using Drucker's (1998) thesis of complexity theory as our premise, we are contending that wicked problems faced by organizations can be understood within the eight dimensions of the UN Human Security Framework, which is consequently presented in this paper. Building a holistic view is important because increases in security at one dimension do not replace nor eliminate demands at other dimensions. On the contrary, insecurity at one of the eight dimensions affects the other dimensions. Understanding the human security as greater than the sum of its parts implies better coordination 
between dimensions and helps in developing more sustainable approaches and policies to address the wicked problems at the intersection of the various dimensions.

Complexity theory in business is based on the concept of chaos theory, general systems theory, and other related fields that attempt to explain complex phenomenon (Yawson, 2013). Chaos theory studies the behavior of dynamical systems that are highly sensitive to initial conditions - a response popularly referred to as the butterfly effect. Small differences in initial conditions yield widely diverging outcomes for such dynamical systems, rendering long-term prediction difficult in general (Kellert, 1993). In business, complexity theory is typically used as a tool to study changing systems to properly function within complex adaptive systems (UhlBien \& Arena, 2017; Uhl-Bien, Marion, \& McKelvey, 2007). The emergence of organizational theory based on complexity theory has provided new views for examining and theorizing organizational activities (Styhre, 2002). Applying core tenets of complexity theory is useful for solving the "crucial problem" in strategic management- describing, explaining, and predicting firm heterogeneity (Brenes, Ciravegna, \& Woodside, 2017). In this paper, we discuss the Human Security Framework as a Complex Adaptive Leadership approach in addressing Wicked Problems. We first explore complexity theory in more detail and its influence on social systems using gender bias and terrorism as examples. We then discuss wicked problems as seen through the UN human security framework.

\section{COMPLEXITY THEORY}

Complexity theory can be regarded as an emerging model for understanding the complex dynamics underlying processes (Frenken, 2006). The importance of complexity theory is its ability to model more complex interaction structures with less parameter, lending itself to two frames of reference, the complex interaction structures of components in systems and the interactions between network innovations (Frenken, 2006). The rapid pace required by organizations to develop and change may cause them to adjust their methodologies. Organizations have to cope with the complexity of their environment to survive (Schneider, Wickert, \& Marti, 2017). Sustainability within this type of environment means institutionalizing an orientation toward change, not to be reactive but instead encourage proactivity (Brown \& Gioia, 2002). Instead of controlling interactions, organizations need to focus on one main interest while allowing leaders and followers to interact, dispersing leadership (Brown \& Gioia, 2002).

The complexity of the social structures and the interactions between leadership and employees is a commitment to a corporate vision, decentralizing and distributing leadership activities across the organization. The precise structure of the relationships affects the performance of the network regarding speed and diffusion (Frenken, 2006). Organizations created this way share information, knowledge, leadership and learning allowing for the collective network to be in a better position to respond swiftly to change (Brown \& Gioia, 2002). Complexity models have the advantage of capturing more realistic features of processes while avoiding the danger of overparameterization (Frenken, 2006).

\section{Modeling Complexity}

Modeling tools can be used to help organization scientists better understand complexity and the individual behavior that guides the action of the larger organization or society. Anderson (1999), in his perspectives on 
complexity theory and organization science, asserts that complex adaptive system (CAS) models represent a genuinely new way of simplifying the complex. Anderson (1999) describes four elements that characterize these models:

- Agents with schemata, which assumes that the behavior of an agent (an individual, group, or coalition of groups within an organization) is dictated by a schema.

- Self-organizing networks sustained by importing energy, which asserts that the behavior of a particular agent depends on the expression of some subset of all the agents in the organization. These agents are connected by feedback loops.

- Coevolution to the edge of chaos is the dynamic coevolution of individuals where small changes in behavior can create small, medium or large changes in outcomes.

- Recombination and system evolution is the evolution of organizations by the entry, exit, and transformation of agents within the complex adaptive system.

There are several other ways of modeling complexity. Anderson (1999) noted that another way of modeling complexity is to examine regularity that emerges from the interaction of individuals connected together in complex adaptive systems. This is further illustrated by Nicolas Perony, (2013) in a TED Talk where he stated that the complex is not complicated. The complex is made of many interacting parts, and the whole is greater than the sum of its parts. Finding simple rules, or the regularity that emerges from interaction helps to simplify complexity.

\section{Perspectives on Organizational Change: Systems and Complexity Theories}

The most prevalent trends in contemporary organizations are toward continuous and pervasive change and increasing interdependencies. Systems theory is a concept that can be generalized across various systems and is concerned with how systems operate and integrates a broad range of systems by naming and identifying patterns common to all of them (Yawson, 2013). Its distinction between open and closed systems considered the external environment and how an organization's lack of coordination with it might inhibit growth (Schneider et al., 2017). Boulding (1956) presents an interesting classification of levels of systems. The hierarchical approach was significant as it classified systems according to common properties. By knowing the class, one can identify the systems properties without having to observe the system. Despite the enormous benefits of systems theory, failure to specify what is meant by a system failure to provide immediate answers in rapidly changing environments or offering a way forward when constituents of a system conflict are some of systems theory limitations (Amagoh, 2008).

Complexity theory is a more transformational model, defined as the measure of heterogeneity or diversity in internal and environmental factors such as customers, suppliers, socio-politics, and technology (Anderson, 1999; Anning-Dorson, 2017; Kaufmann, Czinkota, \& Zakrzewski, 2015). An essential feature of complexity theory is its concept of adaptive systems. Complex systems' large number of interacting elements, its dissipative structures that absorb external pressure while an organization holds its structure, and the system's ability for self-organization and 
adaptation are features that make it efficient. The system also tends to exhibit emergent properties or new behaviors when the parameters of the system change developing new strategies, marketing tactics, and alliances. Systems and complexity theories allow insight into how subsystems of an organization interconnect and how they cope with continuous change providing a conceptual foundation on how they may proactively and collectively solve and adapt solutions.

\section{Complexity Leadership and Terrorism:} Complexity Leadership has been found to work exceptionally well within the Al-Qaeda network (Marion \& Uhl-Bien, 2003). Al-Qaeda's leadership structure is decentralized and flows from the bottom up. The interactive dynamics shape the leadership structure as opposed to the leaders within the system creating the structure. The complexity of the multiple networks along with the aggregation of loosely connected cells pulled together under one religious ideology lends itself to complex adaptive leadership. The dynamics that terrorist operate within are complex and varied. The operators at the ground level are empowered to adapt to ever-evolving complex conditions. Al-Qaeda and other terrorist cells are very diverse, composed of multiple groups, operate in secrecy, and they conduct business without generating records. Their surveillance and intelligence gathering mechanisms as well as securing of resources and funds are done in secret. They operate using nontraditional guerilla warfare tactics; the leadership is indirect and decentralized. They have their own training camps, mosques in several countries, and allies around the world. Innovation, interdependency, networking, and adaptability are fostered within this dynamic system (Marion \& Uhl-Bien, 2003).
These phenomena foster Complex Adaptive Leadership.

Because Complexity Leadership in the context of Al-Qaeda, for example, is a condition of existing dynamic factors rather than a structure created by the leadership it continues to survive the loss of known cell leaders. The leadership style and construction is not confined to a person or leader. There is no clear distinction between followers and leaders, but each cell or terrorist strives because of interdependency. This is similar to Nicolas Perony's (2013) bats study that illustrates the fission-fusion dynamics of roosting bats. The splitting and merging of bats into subgroups creates a network, which continues to thrive even after losing a significant number of its members. As long as there are shared vision and mission along with on-going multiple interrelations nurtured by Complexity Leadership, Al-Qaeda, for example, will continue to strive, refocus and sustain itself (Marion \& Uhl-Bien, 2003).

\section{Complexity and Gender Bias.} Complexity theory provides a framework for understanding factors that influence gender bias (Hogue, 2016; Hogue \& Lord, 2007; Tran, 2016). Even in today's modern world, women continue to face many obstacles in breaking the 'glass ceiling'(Tran, 2016). There are fewer women acquiring leadership roles at the highest levels of an organization compared to their male counterparts. Complexity theory proposes that organizations are best understood as "complex systems" comprised of a hierarchy of network of relationships (Hogue \& Lord, 2007). Gender bias is evident in top-down networks with those of greater power and prestige at the top holding a more directive role while those individuals with less power, generally women hold a more supportive role. Men more often display high- 
status behavior such as dominance and defectiveness and women display more of a supportive and helpful low-status. This distinction is made based on the belief that men are perceived to be strong, competent and when under pressure, can react less emotionally and can handle stress in a different manner (Hogue \& Lord, 2007). Women, on the other hand, are at a disadvantage and tend to be generalized as warm, weak and react emotionally to a situation rather than strategically and do not handle stress effectively (Tran, 2016). To change the idea of gender bias, organizations will need to evolve and change to improve the general perceptions of gender bias in leadership. Complexity theory provides an opportunity to address this important leadership problem, "but it also shows why multiple solutions applied at individual, group, and organizational levels all may be required to change the way agents and systems of agents respond to potential female leaders"(Hogue \& Lord, 2007:370).

\section{THE WICKED PROBLEM CONSTRUCT}

Organizations in the forefront of global change face significant complex social and environmental issues. These issues fit well the definition of adaptive challenges or wicked problems as outlined within the discussion of complexity theory above. The Wicked Problem Construct a concept developed in 1973 by University of California-Berkeley professors Horst W.J. Rittel and Melvin M. Webber (Rittel \& Webber, 1973). Addressing Wicked Problems has roots in social policy and planning, and has been adopted by the international business community as an essential strategy tool. It remains useful in policy-making arenas to interpret complex systems. Wicked Problems are large, messy, complex, and systemic, and include many of the most challenging issues we face, from global poverty and climate change to local issues of failing education systems and lack of affordable housing (Sherman \& Peterson, 2009; Yawson, 2015). There are no easy solutions to Wicked Problems. Enormous progress can be made in alleviating them, but they will remain.

Organizations can achieve their missions and maximize resources by adopting a Wicked Problem construct, which enables them to:

- Define the qualities of Wicked Problemssocial, political, economic, and scale - of social change issues they are attempting to ameliorate (Peterson, 2009).

- Identify and test one or more potential strategies including their time frames for impact, the likelihood of impact, and the risks associated with the Wicked Problem and the strategies being tried (Peterson, 2009).

- Create enduring and rigorous learning opportunities for organizations and stakeholders around Wicked Problems as part of the program and operations (Peterson, 2009).

A commitment to using a Wicked Problems construct demands that leadership approaches organizational development in a new way. It requires creating, nurturing, and continually reinforcing an organizational culture dedicated to open and honest learning and adaptation, communication, and diverse stakeholder involvement. It also requires organizations to let go of the idea or need to have the right or only answers, to focus on short-term outcomes and impacts, and to control the process unilaterally. These commitments often mean a substantial change in institutional culture achieved only through ownership by leaders throughout the organization. Leaders will need to listen to the song beneath the words (Heifetz, Grashow, \& 
Linsky, 2009). Several change management strategies can help organizational leaders move their organizations from a theoretical Wicked Problems construct to implementing it as a practice and culture.

Systems Thinking in Addressing wicked problems

Systems thinking approach as part of complex adaptive leadership suitable to address wicked problems. Systems thinking is predicated on the principles of systems theory in that the constituent parts of a system will exhibit different behavior and properties when viewed in isolation from the whole (Yawson, 2013). To understand a system requires studying the systems relationships that exist between the various parts that work in concert to determine the behavior of the system. The primary concern of systems thinking is, therefore, how the "whole" is seen as well as its fit and relationship to its environment (Yawson, 2013). A secondary emphasis is placed on the component parts of the system.

Wicked Problems, as envisioned by Rittel and Webber (1973), captured the multidimensional nature of systems and allowed planners and policy professionals to describe the challenges they faced, "whether concerns over the location of a freeway, the adjustment of a tax rate, the modification of school curriculum, the confrontation of crime... or The System... as an evil source of misery and suffering" (Rittel and Webber, 1973: 158). This is the reason we are contending that wicked problems faced by organizations could be understood within the eight dimensions of the UN Human Security Framework, which is consequently presented in this paper. Building a holistic view is important because increases in security at one dimension do not replace nor eliminate demands at other dimensions. On the contrary, insecurity at one of the eight dimensions affects the other dimensions. Understanding the human security as greater than the sum of its parts implies better coordination between dimensions and helps in developing more sustainable approaches and policies to address the wicked problems at the intersection of the various dimensions.

\section{The Importance of Treating Wicked Problems in a Systemic Way}

The traditional approach to problemsolving in organizations is rooted in a linear and mechanistic view of the universe (Conklin, 2006). This approach to problem-solving has served organizations and led necessary changes in the past, including several success stories during the last two decades (such as the Green Revolution). Such approach, however, no longer allows us to meet the demands of today's world. The problem is that often business leaders are stuck with business practices rooted in linear epistemology which have worked for them in the past but are not suited in addressing wicked social change problems.

Camillus, (2008) argues that the Wicked Problems frame has been mostly missing from organizational development discussions. He based his conclusions on studying approximately 30 enterprises from around the world and tracking strategies within DuPont's pharmaceutical business to understand how companies draw up strategies when returns are highly uncertain and accrue only in the long run. A possible explanation is that organizations are still stuck in the industrial revolution mindset, and a change of mindset requires a new revolution.

The use of systems theory in organizations for human development has mostly been restricted to hard systems theory that uses simulations and takes a narrow view at the conversion of inputs into outputs for the 
attainment of particular goals and objectives (Engel, 1997). Hard systems are valuable for tame or as Heifetz et al. (2009) described type I problems, that is, problems that can reasonably be quantified (Yawson, 2015). The most important drawback of its use is that it is not applicable to addressing wicked problems or adaptive challenges.

\section{WICKED PROBLEMS AS SEEN THROUGH}

THE UN HUMAN SECURITY

\section{FRAMEWORK}

Although the global wealth appears to grow, global poverty levels remain alarmingly high and impact negatively on human development. Human security is a wide-ranging concept that demonstrates the weaknesses and vulnerabilities of human beings, as well as their potential. Opportunities for growth and development are increasingly linked, yet can become sources of insecurity (Onuoha, 2009). This is important both for understanding the origins of such threats to human life and for

providing strategies to address them. Intended to encompass freedom from fear (violence) as well as freedom from want (poverty), human security is a multidimensional construct that represents a shift from notions of security that are nationcentered to one that is people-centered (UNDP, 1994). Protection of national borders is irrelevant to threats that lie within them (e.g., genocide, terrorism) as well as those that lie without (e.g., global warming, nuclear holocaust). No human security index comparable to the Human Development Index currently exists, and data that are available for some of the individual dimensions are typically not disaggregated by sex. While yet to be fully operationalized, the UN Human Development Report identified seven dimensions required for human security: economic security, food security, health security, environmental security, personal security, community security, political security (UNDP, 1994). The Women Funding Network (WFN) also included an eight dimension (Education), which is included in this paper.

Building a holistic view is important because, increases in security at one dimension do not replace nor eliminate demands at other dimensions. On the contrary, insecurity at one of the eight dimensions affects the other dimensions. Understanding the human security as greater than the sum of its parts imply better coordination between dimensions and help in developing more sustainable programs and operations to address the wicked problems at the intersection of the various dimensions.

To bring more context to the discussion, we have summarized the role of each human security dimension in the context of wicked problems:

1. Economic security requires an assured income from employment or some publicly financed safety net to fulfill basic needs. The informal sector usually provides the most insecure employment. With multiple and complex challenges facing the world economy, organizations should see problems through economic security dimensions.

2. Community Security is a non-income Human Security Dimension ranging from insecure environments, conflict, and violence to social discrimination in which people of particular communities are trapped in exploitative relationships of power and patronage.

3. Personal Security is also one of the nonincome dimensions of the Human Security Frame. It encompasses different subdimensions including personal safety 
from bodily injury, protection from armed robbery, prevention of domestic violence, female genital mutilations, and child abuse, among others. Domestic violence is arguably the biggest threat to personal security across the globe. It is the intentional and persistent abuse of anyone in the home in a way that causes pain, distress or injury such as battering of intimate partners and others, sexual abuse of children, marital rape, and traditional practices that are harmful to women, typically female genital mutilation and widowhood rites (Ishola, 2016).

4. Political Security is also one of the nonincome measures of Human Security ranging from the threats of limited citizenship (lack of a meaningful political voice) to spatial disadvantage (exclusion from politics, markets, resources, etc., owing to geographical remoteness.

5. Food Security which requires that all people at all times have both physical and economic access to basic food. Food insecurity is the most extreme form of poverty and vulnerability among the dimensions of Human Security. Families who are not food secure cannot afford to meet their most basic need for food.

6. Health Security which aims to guarantee minimum protection from diseases and unhealthy lifestyles

7. Environmental security requires protection from short- and long-term devastation of nature and destruction of the environment. Deforestation, the construction of large dams, soil erosion, siltation of reservoirs, water logging and salinity

8. Education Security. Education is an important dimension of human security and enables individuals to make informed choices, broaden their horizons and opportunities and to have a voice in public decision making. Lack of access to education poses a severe threat to human security 


\section{Human Security Index}

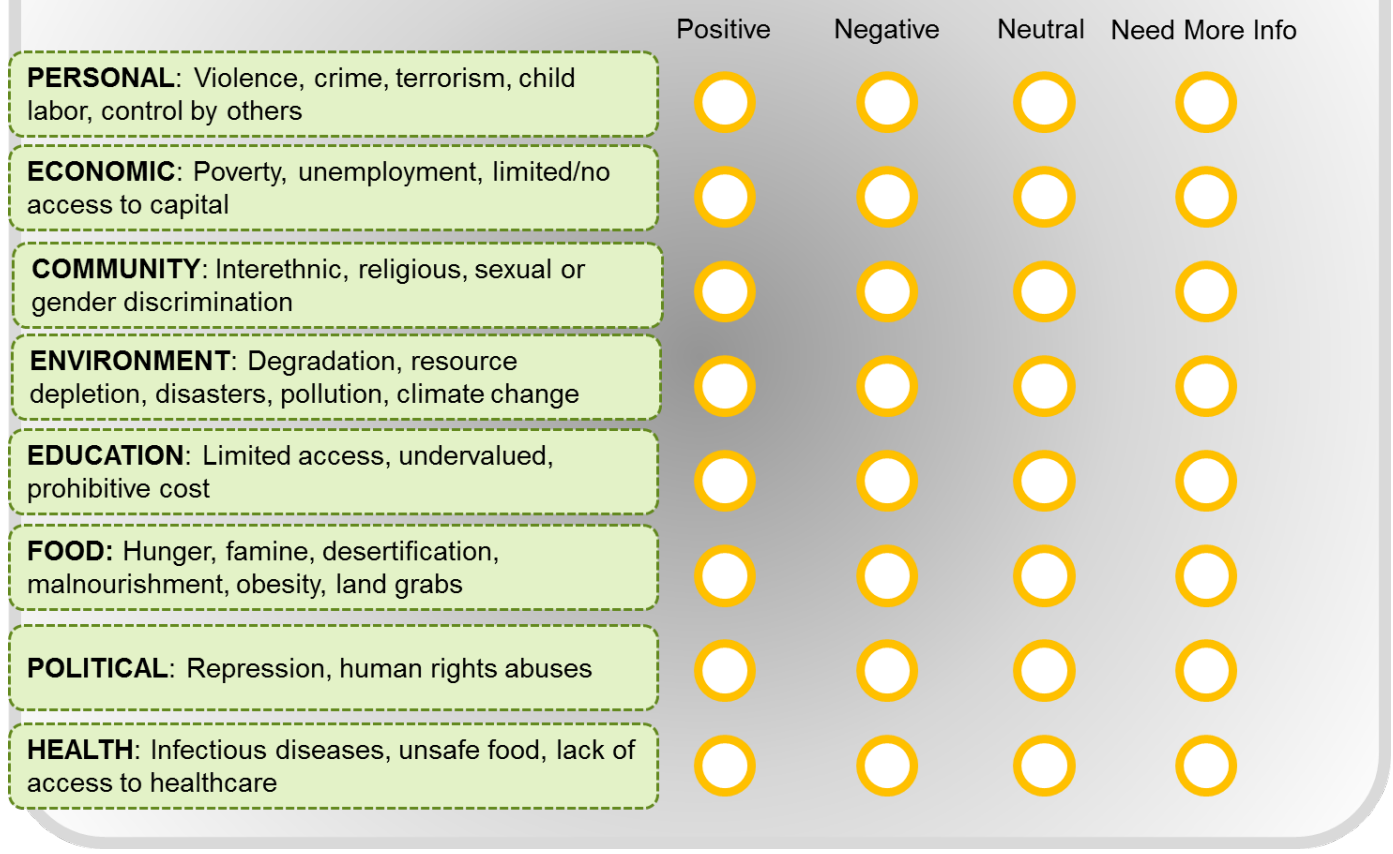

(C) Authors

Figure 2: Human Security Index Mapping

For business organizations venturing into sustainability and social sector issues, every situation and challenge should be mapped against these dimensions so that unintended consequences of addressing wicked problems within just one or two dimensions and creating even further challenges in other dimensions can be curtailed. Figure 2 shows the human security index and the various check marks to determine the human security dimensions the problem is situated. This Human Security Index offers a new way to understand the dynamic complexity of wicked problems and a new framework for designing programs and operations by organizations. The human security framework significantly improves our ability to anticipate, diagnose, and mitigate the sources of wicked problems.

\section{CONCLUSION \& RECOMMENDATIONS}

Systems and complexity theories allow insight into how sub-systems of an organization interconnect and how they cope with continuous change providing a conceptual foundation on how they may proactively and collectively solve and adapt solutions. As public trust of government declines, these systems can also help public institutions adapt to a changing environment by reducing bureaucracy, organizing on a more local or less formal basis and designing more entrepreneurial public organizations (Amagoh, 2008).

The global environment is an everchanging entity. Complexities, or challenges faced by leaders that bring with it instances of uncertainty and the capacity to be destructive, must be addressed and done so adequately. 
Leaders of the twenty-first century must look to new innovative ways to address new issues not faced by their twentieth-century counterparts.

Drucker's (1998) perspective that management should be viewed as a social enterprise, with a focus on the overall well-being of the humans and the environment in which it operates is a critical aspect of complex adaptive leadership. This is particularly important, as human interests have primarily remained the same; it is the current structures in which business or governmental agencies operate that require change. In a world shifting to that of more uncertainty and complexity, we have witnessed how the intricacies of once multi-level structured twentieth-century companies morphed into the less bureaucratic, free-flowing information exchanging, and adaptable twenty-first-century organizations of today. However, what is being argued is that even more change is required to meet the complexities of the still changing global environment while remaining focused on the human element of it all.

Whether it is global leadership or business leadership, while the challenges faced and the road to desired outcomes may be different, the destination is often the same; which is to be in a desirable position at the end of the day. It is important for leaders to understand their own world/cultural perspective in identifying how it can influence them as leaders. These views are often obscure globally beneficial business/political interests in favor of more ingroup advantages. These observations do not take into consideration the global environment, the arena in which complexities and uncertainty thrive. Therefore, it can be argued that like business, global leaders ought to focus on the people within the in-group (customers/nationals) while brokering relationships with those of the out-group (potential customers/global community) in adequately managing economic and political complexities.

There exists no framework or archetype for a leader to meet all instances of uncertainty nor does there exist a distinct definition of the type of leader that is most suitable to meet these challenges. Situations facing an organizational or global leader, their particular perceptions, and frame of thought are what shape the leader, and in turn dictate her/his actions. However, the trait to be flexible and adaptable when met with these challenges has been identified as a valuable tool to meet and address these issues. Greater understanding of one's environment is invaluable to make life easier for those affected by it. Also, proactive approaches to meet challenges have been shown to be more beneficial than the sit and act reactive method. In sum, it is crucial for leaders to get to know what the world is like outside and plan accordingly to meet the needs of those inside better.

There is the need to put in play an ecosystem model for change. Chaos theory and its offshoots, complexity theory and complex adaptive systems (CAS), are underlined by the features of systems theory, although they may represent a new and distinct generation of thought (Yawson, 2013). These theories maintain that "relationships in complex systems, like organizations, are non-linear, made up of interconnections and branching choices that produce unintended consequences and render the universe unpredictable" (Tetenbaum, 1998: 21). Complexity theory posits "that some events, given our knowledge and technology, are unknowable until they occur, and may indeed be unknowable in advance" (Schneider \& Somers, 2006: 354). Complexity theory includes three interrelated elements that are not accounted for in 
General Systems Theory (GST). These are nonlinear dynamics, in which structures are characterized by high states of energy exchange with the environment and extreme instability (Hickman, 2010); chaos theory which is nonlinear, deterministic (rather than probabilistic), sensitive to initial conditions, and continuous irregularity in the behavior of the system (Taleb, 2007); and adaptation and evolution, in which an ability to modify or change is evidenced by process of interdependent selforganization among individuals or subsystems (Schneider \& Somers, 2006). Within complexity theory, the concept of complex adaptive leadership may provide the best organizational capacity to tame wicked problems. An organization that develops complex adaptive leadership can function as a 'poised' system that can tame wicked problems. The wicked problem construct and the use of the human security framework are coherent actions, not the final solution.

\section{REFERENCES}

Amagoh, F. 2008. Perspectives on organizational change: systems and complexity theories. The Innovation Journal: The Public Sector Innovation Journal, 13(3): 1-14.

Anderson, P. 1999. Perspective: Complexity Theory and Organization Science. Organization Science, 10(3): 216-232.

Anning-Dorson, T. 2017. How much and when to innovate. European Journal of Innovation Management, 20(4): 599-619.

Boulding, K. E. 1956. General Systems TheoryThe Skeleton of Science. Management Science, 2(3): 197-208.

Brenes, E. R., Ciravegna, L., \& Woodside, A. G. 2017. Taking the Complexity Turn in Strategic Management Theory and Research.
The Complexity Turn: 21-66. Cham: Springer International Publishing.

Brown, M. E., \& Gioia, D. A. 2002. Making things click. The Leadership Quarterly, 13(4): 397-419.

Camillus, J. 2008. Strategy as a wicked problem. Harvard Business Review, May: 99-106.

Conklin, J. 2006. Wicked problems and social complexity. (J. Conklin, Ed.)Dialogue Mapping: Building Understanding of Wicked Problems. Hoboken, NJ: John Wiley.

http://cognexus.org/wpf/wickedproblems.pd f.

Drucker, P. F. 1998. Management's New Paradigms. Forbes, 162(7): 152-170.

Engel, P. G. H. 1997. The social organization of innovation. A focus on stakeholder interaction. (P. G. H. Engel, Ed.). Amsterdam, The Netherlands: Royal Tropical Institute.

Frenken, K. 2006. Technological innovation and complexity theory. Economics of Innovation and New Technology, 15(2): 137-155.

Heifetz, R. A., Grashow, A., \& Linsky, M. 2009. The Practice of Adaptive Leadership: Tools and Tactics for Changing Your Organization and the World. Boston, MA: Harvard Business Press.

Hogue, M. 2016. Gender bias in communal leadership: examining servant leadership. Journal of Managerial Psychology, 31(4): 837-849.

Hogue, M., \& Lord, R. G. 2007. A multilevel, complexity theory approach to understanding gender bias in leadership. Leadership Quarterly, 18(4): 370-390.

Ishola, S. A. 2016. Domestic Violence: The Nigerian Experience. Asia-Africa Journal 
of Mission and Ministry, 13: 3-16.

Jayanti, E. B. 2011. Through a Different Lens: A Survey of Linear Epistemological Assumptions Underlying HRD Models.

Human Resource Development Review, 10(1): 101-114.

Kaufmann, H. R., Czinkota, M. R., \& Zakrzewski, M. 2015. B2B and internal relationships and curative international marketing: A polish case study. Industrial Marketing Management, 51: 69-78.

Kellert, S. H. 1993. In the Wake of Chaos: Unpredictable order in dynamical systems. Chicago, IL: University of Chicago Press.

Lane, D. A., \& Down, M. 2010. The art of managing for the future: leadership of turbulence. Management Decision, 48(4): 512-527.

Marion, R., \& Uhl-Bien, M. 2003. Complexity Theory and Al-Qaeda: Examining Complex Leadership. Emergence, 5(1): 54-76.

Nicolas Perony. 2013. Puppies! Now that I've got your attention, complexity theory | TED Talk | TED.com. Zurich, Switzerland: TEDxZurich 2013. https://www.ted.com/talks/nicolas_perony_ puppies_now_that_i_ve_got_your_attention _complexity_theory.

Onuoha, F. 2009. Why the poor pay with their lives: oil pipeline vandalisation, fires and human security in Nigeria. Disasters, 33(3): 369-389.

Peterson, G. 2009. Wicked Problem Construct: Business and Social Sector Strategies for Global Change. Saint Paul, MN: Headwaters Group/Partners for Change, Global.

Rittel, H., \& Webber, M. 1973. Dilemmas in a general theory of planning. Policy Sciences, 4(December 1969): 155-169.
Schneider, A., Wickert, C., \& Marti, E. 2017. Reducing Complexity by Creating Complexity: A Systems Theory Perspective on How Organizations Respond to Their Environments. Journal of Management Studies, 54(2): 182-208.

Schneider, M., \& Somers, M. 2006. Organizations as complex adaptive systems: Implications of Complexity Theory for leadership research. The Leadership Quarterly, 17(4): 351-365.

Senge, P., Smith, B., Kruschwitz, N., Laur, J., \& Schley, S. 2010. The necessary revolution. New York, NY: Crown Publishing Group.

Sherman, J., \& Peterson, G. 2009. Finding the Win in Wicked Problems: Lessons From Evaluating Public Policy Advocacy. The Foundation Review, 1(3): 87-99.

Styhre, A. 2002. Non-linear change in organizations: organization change management informed by complexity theory. Leadership \& Organization Development Journal, 23(6): 343-351.

Surdu, G., \& Potecea, V. 2013. PARADIGM CHANGES IN THE INTERNATIONAL MANAGEMENT ENVIRONMENT AND IN THE ORG...: EBSCOhost. Romanian Economic and Business Review, 8(1): 5156.

Taleb, N. N. 2007. The Black Swan. The Impact of the Highly Improbable. New York, NY: The Random House Publishing Group.

Tetenbaum, T. J. 1998. Shifting paradigms: From Newton to Chaos. Organizational Dynamics, 26(4): 21-32.

Tran, B. 2016. Gendered Leadership in Multinational Corporations: Gendered Social-Organizations: An Analysis of a Gendered Foundation in Organizations. In Ş. Erçetin (Ed.), Women Leaders in Chaotic 
Environments: 207-233. Berlin Heidelberg: Springer.

Uhl-Bien, M., \& Arena, M. 2017. Complexity leadership: Enabling people and organizations for adaptability. Organizational Dynamics, 46(1): 9-20.

Uhl-Bien, M., Marion, R., \& McKelvey, B. 2007. Complexity Leadership Theory: Shifting leadership from the industrial age to the knowledge era. Leadership Quarterly, 18(4): 298-318.

UNDP. 1994. HUMAN DEVELOPMENT

REPORT 1994. (B. Ross-Larson, A. Strong,
K. Bieler, J. Peabody, E. Hanlon, et al., Eds.). New York, NY: Oxford University Press.

Yawson, R. M. 2013. Systems Theory and Thinking as a Foundational Theory in Human Resource Development-A Myth or Reality? Human Resource Development Review, 12(1): 53-85.

Yawson, R. M. 2015. The "wicked problem construct" for organisational leadership and development. International Journal of Business and Systems Research, 9(1): 6785. 